\title{
IMPLEMENTASI BIMBINGAN ISLAMI BAGI MUSLIMAH PADA MASA NIFAS DI RS ISLAM SULTAN AGUNG SEMARANG
}

\author{
Machfudloh $^{1}$, Hanifatur Rosyidah ${ }^{2}$, Nurul Fadlila ${ }^{3}$ \\ 1,2, 3 Prodi Kebidanan FK Unissula Semarang \\ *Email : machfudloh@unissula.ac.id
}

\begin{abstract}
Abstrak
Bimbingan islami bagi muslimah pada masa nifas merupakan wujud kepedulian RSI Sultan Agung Semarang agar tebentuknya rasa sayang ibu dan rasa sayang ke bayinya. Bimbingan yang dilakukan yaitu penjelasan darah nifas, menyusui secara islam, dan kewajiban orang tua terhadap anak.Bimbingan masa nifas ini dilakukan dengan tujuan agar pada masa nifas berjalan dengan baik sesuai kaidah islam, namun peran serta tenaga kesehatan, pasien, keluarga dan steakholder menjadi kunci terwujudnya tujuan tersebut. Tujuan penelitian adalah menganalisa sejauh mana implementasi bimbingan islami bagi muslimah pada masa nifas di RSI Sultan Agung Semarang. Penelitian ini menggunakan jenis penelitian deskriptif analitis. Variabel independent adalah implementasi.Variabel dependent adalah hambatan-hambatan yang terjadi. Populasi penelitian ini adalah tenaga kesehatan, pasien, dan steakholder di RSI Sultang Agung Semarang. Lokasi di RSI Sultan Agung Semarang. Data yang digunakan data primer dengan instrument berupa lembar kuesioner/wawancarat. Analisa data menggunakan metode kualitatif. Hasil Penelitian adalah bimbingan islami bagi muslimah pada masa nifas di RSI Sultan Agung Semarang sudah dilaksanakan secara langsung (face to face) maupun tidak langsung sejak tahun 2012, Materi yang disampaikan mengalami perbaikan buku sebanyak 7 kali dengan adanya masukan dari pasien, pasien termotivasi, menambah ilmu pengetahuan dan memberikan dukungan moral spiritual pada pasien dan keluarganya. Adapun hambatannya adalah jumlah petugas kerohaniaan BPI (Bimbingan dan pelayanan Islami) yang tidak seimbang dengan jmlah pasien, dimana jumlah petugas hanya 4 orang petugas kerohanian perempuan yang dikhususkan untuk memberikan bimbingan bagi wanita hamil, melahirkan dan menyusui. Selain itu hambatan lainnya adalah jam kerja petugas kerohaniaan yaitu jam 07.00-14.00 dan tidak shif, sehingga terdapat pasien yang tidak mendapatkan bimbingan tersebut.
\end{abstract}

Kata kunci : Implementasi, Bimbingan Islami, Nifas

\begin{abstract}
Implementation Of Islamic Guidelines For Muslimah In The Principles In Sultan Agung Semarang Islamic Hospital. Islamic guidance for Muslim women in childbirth is a form of concern at the Sultan Agung Hospital in Semarang so that the formation of maternal affection and affection to her baby. Guidance is carried out namely the explanation of puerperal blood, breastfeeding in Islam, and the obligations of parents to children. Guidance for childbirth is carried out with the aim that during the puerperium goes well according to Islamic rules, but the role of health workers, patients, families and steakholders are key the realization of these goals. The purpose of the study was to analyze the extent of the implementation of Islamic guidance for Muslim women during the childbirth at RSI Sultan Agung Semarang. This research uses descriptive analytical research. The independent variable is implementation. The dependent variable is the obstacles that occur. The population of this research is health workers, patients, and steak holders at Sultang Agung Hospital, Semarang. Location at RSI Sultan Agung Semarang. The data used primary data with instruments in the form of questionnaire / interview sheets. Analysis of data using qualitative methods. The results of the study are Islamic guidance for Muslim women in childbirth at RSI Sultan Agung Semarang has been carried out directly (face to face) or indirectly since 2012, the material submitted improved books 7 times with the input from patients, motivated patients, adding science and provide spiritual moral support to patients and their families. The obstacle is that the number of BPI (Islamic Guidance and Islamic service) spiritual officers is not balanced with the number of patients, where there are only 4 female spiritual officers who are devoted to providing guidance for pregnant, childbirth and breastfeeding women. Besides other obstacles, the clerical officer working hours are 07.00-14.00 and not shif, so there are patients who do not get the guidance.
\end{abstract}

Keywords: Implementation, Islamic guidance, Postpartum 


\section{Pendahuluan}

Masa nifas (puerperium) adalah masa setelah keluarnya placenta sampai alat-alat reproduksi pulih seperti sebelum hamil dan secara normal masa nifas berlangsung selama 6 minggu atau 40 hari (Varney, 2009). Nifas menurut bahasa berarti melahirkan. Menurut istilah syara', Nifas adalah darah yang keluar dari kemaluan seorang wanita setelah melahirkan (wiladah), dan sebelum melampaui 15 hari dan malam dari lahirnya anak (Salim, 2012).

Asuhan masa nifas diperlukan dalam periode ini karena merupakan masa kritis baik ibu maupun bayinya. Diperkirakan $60 \%$ kematian ibu akibat kehamilan terjadi setelah persalinan dan 50\% kematian masa nifas terjadi dalam 24 jam pertama. Masa neonatus merupakan masa kritis bagi kehidupan bayi, 2/3 kematian bayi terjadi dalam 4 minggu setelah persalinan dan $60 \%$ kematian BBL terjadi dalam waktu 7 hari setelah lahir. Dengan pemantauan melekat dan asuhan pada ibu dan bayi pada masa nifas dapat mencegah beberapa kematian ini (Sarwono, 2008).

Dalam masa nifas dukungan atau bimbingan dari tenaga kesehatan, keluarga dan lingkungan sangat berpengaruh terhadap masa nifasnya. Banyak ibu nifas yang mengeluh masih takut merawat bayinya, takut menjadi ibu dan takut tidak cantik lagi. untuk itu Asuhan pada masa nifas sangat diperlukan apalagi bimbingan Islami bagi muslimah pada masa nifas.

Rumah Sakit Islam Sultan Agung Semarang sesuai dengan motonya, "mencintai Allah, menyayangi sesama, tidak hanya memperhatikan bidang kesehatan saja, tetapi juga sangat peduli dengan sarana dakwah Islamiyah Salah satunya adalah program bimbingan islami bagi muslimah pada masa nifas sebagai wujud kepedulian terhadap rumah sakit sayang ibu dan sayang bayi.

Beberapa bimbingan yang dilakukan pada saat masa nifas di RSI Sultan Agung semarang diantaranya: penjelasan darah nifas, menyusui secara Islam, dan kewajiban orang tua terhadap anak. Bimbingan tersebut dilakukan dengan tujuan agar tidak jauh dari ajaran islam.

Sejumlah Studi tentang Bimbingan pada Masa Nifas telah banyak dilakukan oleh para peneliti diantaranya Pengaruh bimbingan spiritual islami terhadap kualitas hidup pasien hemodialisis di rsud kabupaten semarang (Kanthi S, dkk, 2014), Pengaruh bimbingan rohani Islam terhadap penurunan tingkat kecemasan $\mathrm{ibu}-\mathrm{ibu}$ hamil anak pertama (studi kasus di klinik bersalin Bidan R. Ardiningsih, AMD. Keb. Rowosari Tembalang Semarang (Husna, Fazat, 2010) dan Bimbingan fiqh wanita pada pasien pasca melahirkan di Rumah Sakit Islam Sultan Agung Semarang (Nur 
$\mathrm{R}$, 2019), dimana didapatkan hasil pelaksanaan bimbingan rohani Islam terhadap pasien pasca melahirkan di Rumah Sakit Islam Sultan Agung Semarang, pada pelaksanaannya adalah tidak jauh berbeda dengan pemberian bimbingan pada pasien rawat inap pada umumnya. Pasien pasca melahirkan di RSI Sultan Agung Semarang mendapatkan perhatian lebih dari pihak rumah sakit (rohaniawan).

Masalah-masalah pada masa nifas yaitu pengeluaran darah nifas, proses menyusui dan hak anak untuk hidup, adzan ditelinga anak yang dilahirkan, menyusui, memberi nama yang baik, mengaqiqahkan anak, mendidik anak tentang agama, mendidik anak tentang agama (shalat, memberikan pengajaran Al-Quran, mendidik adab yang baik), memberi makan dan keperluan lainnya dan rizki yang halal, memberi kasih sayang, dan menikahkannya (Muhammad Bin Shalih, 2015).

Berdasarkan hasil wawancara di Rumah Sakit Islam Sultan Agung Semarang sebagian besar wanita muslimah menyatakan mendapatkan buku panduan ibu nifas secara Islam namun yang memberikan bimbingan islami adalah tenaga kesehatan bukan bagian rohaniawan. Sebagian besar Ibu nifas mengatakan sangat penting bimbingan Islami pada masa nifas terutama tentang pengeluaran darah nifas, proses menyusui dan hak anak untuk hidup menurut Islam.

Berdasarkan latar belakang diatas, peneliti akan mengkaji tentang "Bagaimana implementasi bimbingan Islami bagi muslimah pada masa nifas di Rumah Sakit Islam Sultan Agung Semarang"

\section{Metode}

Penelitian ini menggunakan jenis penelitian deskriptif analitis, bersifat deskriptif karena penelitian ini dimaksudkan untuk memberikan gambaran tentang implementasi bimbingan islami bagi muslimah pada masa nifas di RSI Sultan Agung Semarang dan hambatanhambatan yang terjadi. Populasi penelitian ini adalah tenaga kesehatan, pasien, dan steakholder di RSI Sultang Agung Semarang sejumlah 6 responden. Lokasi di RSI Sultan Agung Semarang. Data yang digunakan data primer dengan instrument berupa lembar kuesioner/wawancarat. Analisa data menggunakan metode kualitatif. Adapun waktu pelaksanaannya adalah 6 bulan yaitu bulan juli-Desember 2018

\section{Hasil}

Hasil penelitian ini merupakan hasil wawancara dengan tenaga kesehatan di RSI Sultan Agung Semarang, Pasien dan steakholder di RSI Sultan Agung Semarang. Adapun hasil penelitian ini adalah sebagai berikut: 


\section{Gambaran Implementasi bimbingan islami bagi muslimah pada masa nifas di RSI Sultan Agung Semarang}

Tabel 1 Karakteristik Pasien

\begin{tabular}{ccccc}
\hline No & Kode & Tanggal/jam wawancara & $\begin{array}{c}\text { Usia } \\
\text { (Tahun) }\end{array}$ & $\begin{array}{c}\text { Pendidikan } \\
\text { Terakhir }\end{array}$ \\
\hline 1 & P1 & Kamis, 3 Jan 2019/11.30 WIB & 25(P1A0) & SMA \\
2 & P2 & Kamis, 3 Jan 2019/12.30 WIB & 30 (P2A0) & SMP \\
3 & P3 & Senin, 7 Jan 2019/11.30 WIB & 28 (P1A0) & S1 \\
\hline
\end{tabular}

Tabel 2 Karakteristik Triangulasi

\begin{tabular}{cccc}
\hline Tanggal/Jam Wawancara & Usia & $\begin{array}{c}\text { Pendidikan } \\
\text { Terakhir }\end{array}$ & $\begin{array}{c}\text { Status } \\
\text { Pekerjaan }\end{array}$ \\
\hline Selasa, 25 Des 2018/08.30 & 35 Tahun & $\begin{array}{c}\text { S2 Pendidikan } \\
\text { Agama Islam }\end{array}$ & $\begin{array}{c}\text { Bagian } \\
\text { kerohaniaan }\end{array}$ \\
\hline $\begin{array}{c}\text { Rabu, 26 Des 2018/08.30 } \\
\text { WIB }\end{array}$ & 26 Tahun & D3 Kebidanan & Bidan \\
\hline $\begin{array}{c}\text { Rabu, 26 Des 2018/11.30 } \\
\text { WIB }\end{array}$ & 31 Tahun & D3 Keperawatan & Perawat \\
\hline
\end{tabular}

\section{Wawancara mendalam dengan Pasien, Bidan, Perawat dan Steakholder}

\section{Tabel 3. Wawancara mendalam dengan Pasien}

\begin{tabular}{|c|c|c|c|}
\hline No & Pertanyaan & & Kata Kunci \\
\hline 1 & $\begin{array}{l}\text { Pemberian buku bimbingan } \\
\text { Islami bagi muslimah pada } \\
\text { masa kehamilan, melahirkan } \\
\text { dan menyusui }\end{array}$ & P1 & $\begin{array}{l}\text { - Mendapatkan buku bimbingan pada saat } 6 \text { jam } \\
\text { setelah melahirkan } \\
\text { - Mendapatkan buku bimbingan pada saat } 3 \text { jam } \\
\text { setelah melahirkan diruang VK RSI Sultan Agung } \\
\text { - Mendapatkan buku bimbingan setelah } 1 \text { hari } \\
\text { melahirkan }\end{array}$ \\
\hline
\end{tabular}

\begin{tabular}{|c|c|c|c|}
\hline 2 & 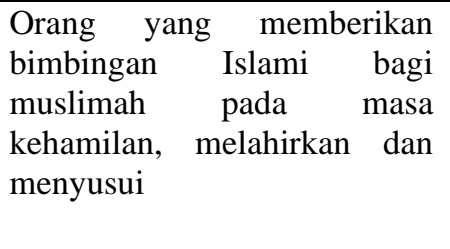 & $\begin{array}{l}\text { P1 } \\
\text { P2 }\end{array}$ & $\begin{array}{l}\text { - yang memberikan bagian Kerohaniaan } \\
\text { - yang memberikan mbaknya yang bagian } \\
\text { kerohanian } \\
\text { - yang memberikan bimbingan adalah bidan dan } \\
\text { perawat saat merawat saya setelah melahirkan, } \\
\text { namun setelah } 1 \text { hari bagian kerohanian }\end{array}$ \\
\hline 3. & $\begin{array}{l}\text { Materi apa saja dalam } \\
\text { Pemberian bimbingan dan } \\
\text { menarik tidak }\end{array}$ & P3 & $\begin{array}{l}\text { - Menyusui dalam islam seperti apa, etika menyusui } \\
\text { dalam islam, hikmah dan keutamaan menyusui, } \\
\text { kewajiban orang tua dan tentang darah nifas } \\
\text { darah nifas seperti apa, cara menyusui dan etika } \\
\text { menyusui dalam islam seperti apa, keuntungan } \\
\text { menyusui dan bagaimana kewajiban orang tua } \\
\text { terhadap anak kita. } \\
\text { - Adzab atau etika menyusi, manfaat menyusi, cara } \\
\text { menyusi yang baik menurut islam, cara bersuci pada } \\
\text { masa nifas/tentang darah haid dan juga bagaimana } \\
\text { tanggung jawab kita sebagai orang tua terhadap } \\
\text { anak kita }\end{array}$ \\
\hline 4. & $\begin{array}{l}\text { Diberikan kesempatan untuk } \\
\text { bertanya tidak dan adakah } \\
\text { umpan balik dari petugas } \\
\text { pemberi bimbingan }\end{array}$ & P1 & $\begin{array}{l}\text { - } \text { sangat baik mbaknya yang memberikan bimbingan, } \\
\text { sampai tidak enak sendiri karena saya nanya-nanya } \\
\text { terus menerus. karena bagi saya sangat menarik } \\
\text { ternyata ada etikanya juga saat menyusui }\end{array}$ \\
\hline
\end{tabular}




\begin{tabular}{|c|c|c|c|}
\hline & & P3 & $\begin{array}{l}\text { - } \text { mbaknya mempersilahkan bertanya dan } \\
\text { memberikan nomor handponnya karena saya mau } \\
\text { nanya-nanya lagi. } \\
\text { bagian kerohanian menerangkan sampai tuntas dan } \\
\text { lemah lembut sampai saya paham, saya bertanya } \\
\text { bagian darah yang keluar pada masa nifas cara } \\
\text { bersucinya seperti apa, apakah sama dengan bersuci } \\
\text { saat menstruasi. }\end{array}$ \\
\hline 5. & $\begin{array}{l}\text { Adakah Manfaat yang didapat } \\
\text { dari pemberian bimbingan }\end{array}$ & $\begin{array}{l}\text { P1 } \\
\text { P2 }\end{array}$ & $\begin{array}{l}\text { - } \text { Sangat banyak manfaatnya, dari saya tidak paham } \\
\text { sampai dengan paham dengan jelas } \\
\text { manfaat banget untuk saya, yang notabennya saya } \\
\text { tidak begitu paham secara islami secara apa etika } \\
\text { pada saat menyusui utamanya } \\
\text { banyak manfaat yang saya dapatkan, sharing ilmu } \\
\text { dengan yang pernah saya dapatkan dari bidan, } \\
\text { perawat maupun dari internet. utamanya adalah } \\
\text { secara islaminya yang paling mengena untuk saya } \\
\text { secara pribadi }\end{array}$ \\
\hline 6. & $\begin{array}{l}\text { Berapa kali } \\
\text { bimbingan }\end{array}$ & $\begin{array}{l}\text { P1 } \\
\text { P2 } \\
\text { P3 }\end{array}$ & $\begin{array}{l}\text { - } 1 \text { kali mendapatkan bimbingan dan buku saya baca- } \\
\text { baca setelah diberikan } \\
\text { - } 1 \text { kali } \\
\text { - } 1 \text { kali dari bagian kerohanian, } 1 \text { kali dari bidan dan } \\
1 \text { kali oleh perawat }\end{array}$ \\
\hline
\end{tabular}

\section{Tabel 4 Wawancara mendalam dengan Steakholder dan tenaga kesehatan}

\begin{tabular}{|c|c|c|c|}
\hline & Pertanyaan & & Kata Kunci \\
\hline 1 & $\begin{array}{l}\text { Pemberian } \\
\text { bimbingan Islami bagu } \\
\text { muslimah pada masa } \\
\text { kehamilan, melahirkan } \\
\text { dan menyusui }\end{array}$ & $\begin{array}{l}\text { BPI } \\
\text { Bid } \\
\text { Per }\end{array}$ & 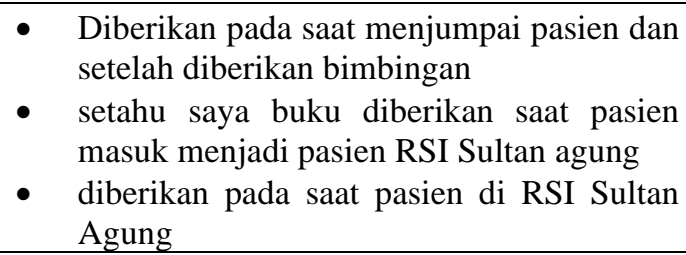 \\
\hline 2 & $\begin{array}{l}\text { Orang yang memberikan } \\
\text { bimbingan Islami bagi } \\
\text { muslimah pada masa } \\
\text { kehamilan, melahirkan } \\
\text { dan menyusui }\end{array}$ & Bid & 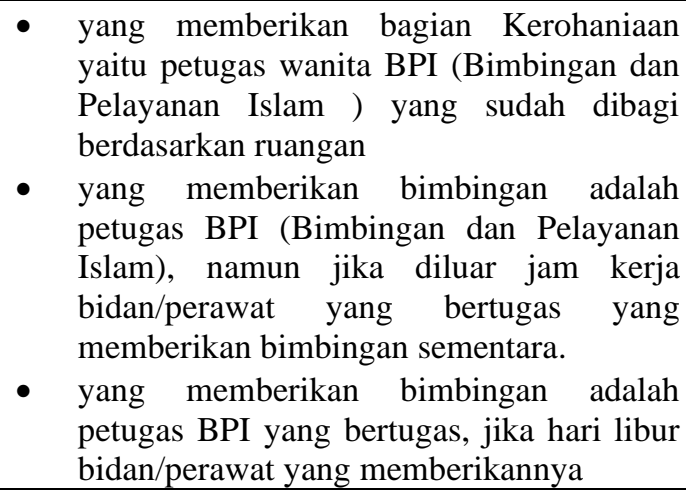 \\
\hline 3 & $\begin{array}{l}\text { Materi apa saja dalam } \\
\text { Pemberian bimbingan } \\
\text { dan menarik tidak }\end{array}$ & BPI & $\begin{array}{l}\text { - } \text { materinya sesuai dengan pada massanya, } \\
\text { kalau pada masa nifas materi yang } \\
\text { diberikan misalnya (konsep dasar menyusui } \\
\text { secara islam, etika menyusui secara islam, } \\
\text { hikmah menyusui, tanggung jawab ortu } \\
\text { kepada anak dan tidak lupa juga tentang } \\
\text { darah nifas seperti apa } \\
\text { materi tentang menyusui, etika menyusui } \\
\text { secara islam, darah nifas dan bagaimana } \\
\text { peran kita sebagai orang tua terhadap anak }\end{array}$ \\
\hline
\end{tabular}


- tentang bagaimana cara menyusui, etika menyusui secara islam dan darah nifas seperti apa

$4 \quad$ Siapa Saja yang berhak memberikan bimbingan
BPI

Bid

Per

\begin{tabular}{llr}
\hline 5 & Adakah & pelatihan \\
- & sebelumnya & bagi \\
& bidan/perawat & dalam \\
& pemberian & bimbingan \\
& Islami bagi & muslimah \\
pada masa & kehamilan, \\
& melahirkan & dan \\
& menyusui
\end{tabular}

Bid

Per
- $\quad$ tanggung jawab utamanya adalah petugas bagian BPI (dimana terdapat 10 BPI yang terdiri dari 4 wanita dan 6 laki-laki), setiap petugas bertanggung jawab 4-6 ruangan. namun jika petugas BPI berhalangan atau tidak ada ditempat, seperti hari libur dibebankan kepada petugas lainnya (seperti bidan/perawat) yang sudah dibekali atau sudah diberi mandatory training tentang fikih wanita dll.

- yang memberikan adalah petugas BPI dan jika petugas berhalangan yang memberikan bimbingan adalah bidan atau perawat yang jaga diruangan tersebut.

- petugas kerohaniaan dalam hal ini adalah BPI, namun jika petugas tidak ada perawat atau bidan yang memberikan dulu, baru besoknya petugas BPI akan memberikan kembali bimbingan tersebut

- namanya bukan pelatihan namun kami namakan mandatory training tentang fikih wanita dll, yang diperuntukkan oleh semua nakes yang bekerja di RSI Sultan Agung Semarang, dimana di refresh setiap 3 bulan sekali

Bid - ada, kajian setiap bulan tentang fiqih wanita dll

- ada berupa kajian-kajian tentang fiqih wanita utamanya dan biasanya setiap 3 bulan sekali kajian dilakukan.

- utamanya adalah SDM (jumlah pasien dengan jumlah petugas BPI) selain itu waktu (pasien masuk ke RSI Sultan Agung tidak tentu di jam kerja) padahal petugas BPI bekerja sesuai ja kerja

- jika dari Petugas BPI tidak bisa memberikan, bidan atau perawat yang harus memberikan bimbingan, kesulitannya adalah jika pasien menanyakan pertanyaan utamanya tentang darah wanita yang tidak normal, disitulah menjelaskannya perlu waktu yang lebih panjang.

- hambatannya adalah saat memberikan bimbingan pasien bertanya tentang hadishadis yang lebih dalam mendasarinya. jadi perawat saat memberikan bimbingan ya tidak sedalam dengan petugas BPI yang ahli didalam Islamnya 


\section{Pembahasan}

A. Analisis Metode Bimbingan Islami bagi muslimah pada masa nifas di RS

\section{Islam Sultan Agung Semarang}

Metode yang diberikan dalam bimbingan islami pada masa nifas yaitu dengan menggunakan metode Langsung (face to face) dan tidak langsung. Dari hasil wawancara dengan 3 pasien didapatkan hasil bahwa semua pasien di RSI Sultan agung mendapatkan buku bimbingan. Hal ini diperjelas juga dari hasil wawancara dengan bidan, perawat dan bagian BPI (Bimbingan dan pelayanan Islam) ketiganya menjelaskan bahwa setiap ada pasien baru yang di RSI Sultan Agung diberikan buku bimbingan.

Metode langsung sesuai dengan pernyataan pasien 1, 2 dan 3 bahwa bimbingan diberikan oleh bagian kerohaniaan dan bidan yang sedang bertugas. Dalam pemberian bimbingan islami bagi muslimah pada masa menyusui bimbingan diberikan oleh petugas BPI, namun jika petugas BPI belum memberikan, bimbingan diberikan oleh petugas kesehatan baik perawat maupun bidan yang bertugas diruang tersebut. Dimana petugas kesehatan sudah dibekali materi sebelumnya (mandatory training) yang di refresh setiap 3 bulan sekali (wawancara, Juli 2018).
Pemberian bimbingan secara langsung dapat menjalin hubungan yang empati serta simpati dengan pasien. Perasaan simpati dan empati yang dimiliki oleh rohaniawan dan bidan pada pasien, hal ini yang merupakan ikatan terbaik untuk menyatukan hati keduanya. Simpati yang diartikan sebagai perasaan seseorang kepada orang lain sangat mendukung keberhasilan proses bimbingan kerohanian (Arifin, 2009). Dapat disimpulkan bahwa pasien membutuhkan perhatian, pelayanan kesehatan dengan baik. Metode yang digunakan pembimbing rohani mampu memberikan perubahan yang baik bagi pasien.

\section{B. Analisis Materi Bimbingan Islami} bagi muslimah pada masa nifas di RS

\section{Islam Sultan Agung Semarang}

Materi yang diberikan berdasarkan hasil wawancara kepada 3 pasien lebih menekankan tentang ibadah berupa penjelasan bagaimana masa nifas (konsep, cara menyusui, darah nifas) maupun tanggung jawab sebagai seorang orang tua. Hal ini sesuai dengan isi buku bimbingan yang diberikan meliputi hukum darah kebiasaan wanita, proses kehamilan dan perkembangan janin dalam kandungan, tuntunan muslimah masa kehamilan, 
menyusui secara Islam, kewajiban orang tua terhadap anak, alat kontrasepsi menurut pandangan islam dan tuntunan memberikan nama anak yang Islami.

Buku ini sudah mengalami revisi/perbaikan dan sekarang adalah cetakan atau terbitan ke-7. Bimbingan sudah dilaksanakan sejak tahun 2012 dan sudah mengalami perbaikan dengan adanya masukan dan pertanyaanpertanyaan dari pasien. Buku ini diberikan secara gratis bentuk kepedulian RSI Sultan Agung dengan tujuan buku bisa dibawa pulang dan bisa dipelajari kembali dirumah untuk dapat disalurkan ke tetangga atau saudara setelah pulang dari RSI Sultan Agung (Wawancara, Juli 2018).

Hal ini sesuai yang di sampaikan oleh (Faqih, 2001) bahwa syari'ah adalah khusus mengenai pokok-pokok ibadah atau hukum-hukum ibadah yang telah dinyatakan dan ditetapkan oleh Allah sebagai peraturan hidup manusia untuk diimani, dan dilaksanakan oleh manusia dalam kehidupannya.

\section{Analisis Tujuan dan Manfaat} Bimbingan Islami bagi muslimah pada masa nifas di RS Islam Sultan

\section{Agung Semarang}

Sebagaimana diungkapkan oleh Hidayanti, 2015 bahwa tujuan bimbingan rohani Islam dengan memberikan dukungan moral spiritual pada pasien dan keluarganya akan menumbuhkan respon spiritual, memberikan pengetahuan dan pemahaman tentang sakit dalam ajaran Islam, dan mengembangkan sikap dan perilaku benar saat menghadapi sakit sehingga pasien dan keluarganya memiliki kemampuan mengatasai masalah yang dihadapi dan akan mempercepat kesembuhan.

Pemberian bimbingan kepada pasien diupayakan agar pasien termotivasi, menambah ilmu pengetahuan yang telah diberikan oleh petugas rohaniawan. Pelaksanaan bimbingan kepada pasien sangat dibutuhkan, karena banyak sekali gangguan jasmani yang disebabkan gangguan psikologis. Sehingga dengan adanya bimbingan tersebut pasien akan merasakan ketenangan dan termotivasi untuk selalu sabar, tabah. Bimbingan islami diupayakan untuk menjaga keimanan pasien dan memberikan pelayanan spiritual. Disinilah pentingnya, dengan adanya pelaksanaan bimbingan pada ibu nifas di Rumah Sakit Islam Sultan Agung Semarang dapat membantu individu atau pasien dalam proses penyembuhan secara psikisnya.

Pada dasarnya fisik dan psikis adalah satu kesatuan eksistensi manusia 
yang menyangkut kesehatannya, sekaligus ada keterkaitan hubungan antara kesehatan fisik dan psikis, bahkan saling mempengaruhi antara keduanya (Rosyidi, 2015).

Dalam melakukan bimbingan, pasien mengungkapkan bahwa para rohaniawan, bidan dan perawat dalam menjelaskannya sangat jelas dan dengan sabar. Hubungan baik tersebut tetap terjalin walaupun pasien sudah keluar dari rumah sakit yaitu melalui komunikasi media telpon. Hal ini diperkuat dengan hasil wawancara mendalam dengan bagian BPI bahwa banyak pasien yang respect dan meminta nomor telepon, jika mereka ingin bertanya-tanya jika mereka masih ada yang kurang paham (wawancara, Juli 2018).

D. Analisis Hambatan Bimbingan Islami bagi muslimah pada masa nifas di RS Islam Sultan Agung Semarang

Dalam memberikan bimbingan islami bagi muslimah pada masa menyusui bagian kerohaniaan yaitu BPI mengungkapkan bahwa hambatan yang dialami adalah jumlah SDM yang masih kurang, dimana SDM yang ada belum sebanding dengan jumlah pasien yang di rawat di RSI Sultan Agung, yaitu hanya ada 8 petugas kerohanian (BPI) dengan jumlah bed lebih dari
400. Selain itu waktu atau jam kerja dari petugas BPI yang tidak ada shif pagi siang ataupun malam, namun sesuai jam kerja yaitu jam 07.00-14.00, sehingga belum semuanya pasien tersentuh bimbingan islami bagi muslimah pada masa menyusui di RSI Sultan Agung Semarang. Upaya yang dilakukan dari tim kerohaniaan untuk mengatasi masalah tersebut adalah memberikan mandatory traning tentang edukasi fikih melahirkan kepada bidan ataupun perawat, dengan tujuan bidan atau perawat bisa memberikan edukasi awal kepada pasien (Wawancara, Agustus 2018). Menurut Hasibuan (2007) Sumber Daya Manusia adalah kemampuan terpadu dari daya pikir dan daya fisik yang dimiliki individu. Sumber daya manusia mempunyai peran utama dalam setiap kegiatan organisasi dapat dilihat dari aspek-aspek yang terdapat didalamnya. Hal ini sejalan dengan hasil penelitian Puri Herawati, 2018 tentang pengaruh sumber daya manusia terhadap kualitas pelayanan. Didapatkan hasil bahwa rata-rata sumber daya manusia berpengaruh terhadap kualitas pelayanan 


\section{Kesimpulan}

Bimbingan Islami bagi muslimah pada masa nifas di RSI Sultan Agung Semarang sudah dilaksanakan sejak tahun 2012 baik secara langsung dan tidak langsung. Materi yang diberikan sudah mengalami perbaikan dibuktikan dengan adanya perbaikan buku sebanyak 7 kali berdasarkan masukan-masukan yang didapat. Adapun tujuan dan manfaat adalah pasien termotivasi, menambah ilmu pengetahuan dan memberikan dukungan moral spiritual pada pasien dan keluarganya. Hambatan yang didapatkan adalah keterbatasan SDM.

Saran untuk RSI Sultan Agung Semarang, diharapkan penambahan jumlah SDM petugas BPI dengan jumlah pasien dan diberlakukannya shift pagi, siang dan malam untuk petugas BPI agar semua pasien tersentuh mendapatkan bimbingan islami bagi muslimah pada masa nifas di RSI Sultan Agung Semarang

\section{Referensi}

Arifin, Isep Zaenal. (2009). Bimbingan Penyuluhan Islam Pengembangan Dakwah Melalui Psikoterapi Islam. Jakarta: Raja Garfindo Persada. Faqih, Ainurrahim. (2001). Bimbingan Dan Konseling Dalam Islam. Yogyakarta: UII Press.
Husna, Fazat. (2010). Pengaruh bimbingan rohani Islam terhadap penurunan tingkat kecemasan ibu-ibu hamil anak pertama (studi kasus di klinik bersalin Bidan R. Ardiningsih, AMD. Keb. Rowosari Tembalang Semarang Kanthi S, dkk. (2014). Pengaruh bimbingan spiritual islami terhadap kualitas hidup pasien hemodialisis di rsud kabupaten semarang

Malayu S. P Hasibuan. (2003). Manajemen Sumber Daya Manusia. Edisi revisi Bumi Aksara, Jakarta: Grasindo

Nur R. (2019) Bimbingan fiqh wanita pada pasien pasca melahirkan di Rumah Sakit Islam Sultan Agung Semarang Salim, Samsudin, Dkk. (2012). Bimbingan Rohani Islami Bagi Muslimah Pada Masa Kehamilan, Melahirkan, Dan Menyusui. Semarang.

Sarwono. (2009). Ilmu Kebidanan. Jakarta : Yayasan Bina Pustaka

Varney, Helen. (2009). Buku Ajar Asuhan Kebidanan Edisi 4. Jakarta : EGC 